\title{
A Double-Blind Cross-over Trial of Amantadine Hydrochloride in Friedreich's Ataxia
}

\author{
A. Filla, G. De Michele, G. Orefice, F. Santorelli, L. Trombetta, \\ S. Banfi, F. Squitieri, G. Napolitano, D. Puma and G. Campanella
}

\begin{abstract}
We performed a double-blind cross-over study with amantadine hydrochloride in 12 patients with Friedreich's disease and 2 with autosomal dominant cerebellar ataxia. Patients were randomly assigned to a placeboamantadine or amantadine-placebo sequence. The interval between the treatments was two weeks. Patients were graded according to a functional ataxia scoring scale and videotaped in basal conditions and $90 \mathrm{~min}$ after a single oral dose of $100 \mathrm{mg}$ amantadine or placebo. Three evaluators independently scored the videotapes. Statistical analysis showed no significant effect of amantadine in Friedreich's disease.
\end{abstract}

RÉSUMÉ: Étude en double insu et chassé-croisé du chlorhydrate d'amantadine dans la maladie de Friedreich. Nous avons administré le chlohydrate d'amantadine à 12 patients atteints de la maladie de Friedreich et 2 patients atteints d'ataxie cérébelleuse dominante au cours d'une étude en double insu et chassé-croisé. Les patients étaient randomisés à la séquence placebo-amantadine ou amantadine-placebo. L'intervalle entre les traitements était de deux semaines. Les patients étaient évalués selon une échelle d'évaluation fonctionnelle de l'ataxie et un enregistrement vidéo était fait dans les conditions de base et 90 minutes après une dose orale unique de $100 \mathrm{mg}$ d'amantadine ou de placebo. Trois évaluateurs ont coté de façon indépendante les enregistrements vidéo. L'analyse statistique n'a pas montré d'effet significatif de l'amantadine dans la maladie de Friedreich.

Can. J. Neurol. Sci. 1993; 20:52-55

Hereditary ataxias are a heterogeneous group of rare diseases. Friedreich's disease (FD) is the most common in the largest series published recently, followed by autosomal dominant cerebellar ataxia (ADCA). ${ }^{1.2}$ Recent advances in molecular genetics have allowed mapping of the FD gene on the centromeric region of the long arm of chromosome $9^{3}$ and the ADCA gene on the short arm of chromosome 6 in some families. ${ }^{4}$

No effective treatment is available for FD or other inherited ataxias. Recently, Peterson et al..$^{5}$ reported a significant improvement in 16 FD patients after a single oral administration of amantadine hydrochloride $(\mathrm{AH})$ in an uncontrolled study. The beneficial effect of $\mathrm{AH}$ was related to a release of dopamine or to an increased GABA content in the CNS. Botez et al. ${ }^{6}$ found that $\mathrm{AH}$ improved reaction and movement times in a group of 12 patients with olivopontocerebellar atrophy in an open trial with $200 \mathrm{mg} /$ day AH for more than 3 months, whereas only right hand movement times improved in a group of 17 FD patients. Since neither study was controlled, we performed a double-blind cross-over study in 12 patients with FD and 2 with ADCA using a single oral AH dose.

\section{Patients and Methods}

All the patients gave informed consent to participate in the trial. Table 1 shows the clinical features of the 14 patients.

Diagnostic criteria for FD were: autosomal recessive inheritance, onset by age 20 years, progressive ataxia of stance and gait and lower limb areflexia. Furthermore, at least one of the following signs was required in the index cases: dysarthria, extensor plantar response or echocardiographic signs of hypertrophic cardiomyopathy. ${ }^{2}$ Two secondary cases (No. 7 and 14) fulfilled the above criteria, but onset was after 20 . Molecular genetic studies were performed in 9 out of 12 FD patients, including the two late onset patients. Polymorphic markers of the centromeric region of the long arm of chromosome 9 cosegregated with the disease locus in all cases.

Diagnostic criteria for ADCA were: autosomal dominant inheritance, onset after 20 years and progressive ataxia of stance and gait. Other possible features were ophthalmoplegia, dementia, optic atrophy, extrapyramidal signs, amyotrophy.' The two brothers with ADCA were from a family with a chromosome 6 linked form.

From the Department of Neurology, Second School of Medicine, Federico II University, Naples and Sanatrix Neurological Institute (G.N., D.P.), Venafro, Italy

Received May 19, 1992. Accepted in final form October 14, 1992

Reprint requests to: Prof. Filla, Clinica Neurologica, Seconda Facolta di Medicina, via Pansini 5, 80131, Napoli, Italy 


\begin{tabular}{rcccccc}
\hline \multicolumn{2}{l}{ Table 1: Clinical Features of Patients } \\
\hline \hline \\
No. & Diagnosis & Sex/Age & $\begin{array}{c}\text { Disease } \\
\text { Duration }\end{array}$ & $\begin{array}{c}\text { IAPS } \\
\text { Stage }\end{array}$ & NUDS & $\begin{array}{c}\text { Trial } \\
\text { Sequence }\end{array}$ \\
\hline 1 & FD & F/23 & 9 & 3 & 37 & AH-PLA \\
2 & ADCA & F/50 & 12 & 3 & 31 & AH-PLA \\
3 & FD & F/20 & 7 & 3 & 39 & AH-PLA \\
4 & FD & F/14 & 10 & 3 & 39 & AH-PLA \\
5 & ADCA & M/43 & 13 & 3 & 33 & AH-PLA \\
6 & FD & M/23 & 20 & 3 & 37 & AH-PLA \\
7 & FD & F/43 & 16 & 2 & 41 & AH-PLA \\
8 & FD & M/13 & 9 & 3 & 37 & PLA-AH \\
9 & FD & M/27 & 21 & 4 & 27 & PLA-AH \\
10 & FD & M/21 & 8 & 3 & 33 & PLA-AH \\
11 & FD & M/42 & 32 & 4 & 23 & PLA-AH \\
12 & FD & F/26 & 13 & 3 & 33 & PLA-AH \\
13 & FD & F/14 & 12 & 4 & 27 & PLA-AH \\
14 & FD & F/25 & 4 & 2 & 48 & PLA-AH \\
\hline
\end{tabular}

IAPS: Inherited Ataxia Progression Scale; ${ }^{7}$ NUDS: Northwestern University Disability Scale; ${ }^{8}$ FD: Friedreich's disease; ADCA: autosomal dominant cerebellar ataxia; $\mathrm{AH}$ : amantadine hydrochloride; PLA: placebo.

Progression of the disease was evaluated according to the Inherited Ataxia Progression Scale ${ }^{7}$ (IAPS: stage 1, affected asymptomatic case; stage 2, symptoms present but mild; stage 3, fully developed disease, the patient cannot work; stage 4, patient confined to wheel-chair). Disability was scored according to the Northwestern University Disability Scale ${ }^{8}$ (NUDS).

Patients were randomly assigned to a placebo- $\mathrm{AH}$ or $\mathrm{AH}$ placebo sequence. The interval between the treatments was two weeks. Patients were tested according to the functional ataxia scoring scale (FASS) suggested by Peterson et al..$^{5}$ with minor modifications (Table 2) and videotaped in basal conditions (about 9 a.m.) and $90 \mathrm{~min}$ after an oral administration of placebo or a $100 \mathrm{mg}$ tablet of $\mathrm{AH}$. At the same times, manual dexterity (modified pegboard test ${ }^{7}$ score $=$ number of tubes placed into a rack in $60 \mathrm{~s}$ ) and writing tests (signature and geometric design; score $=0-20$ ) were performed. Subjective patient evaluation of the treatment and side effects were also recorded.

After the completion of the trial three blinded evaluators independently scored the videotapes and the writing tests. The evaluators were experienced neurologists (AF, GDM, GO) who did not follow the patients during the trial.

The mean coefficient of variation of the FASS total score between examiners and days (first and second basal) was calculated. The Friedman test was used to evaluate modifications of FASS (total and subtotal scores) and other tests. Pearson and Spearman coefficients were used to study FASS/NUDS and FASS/IAPS correlations, respectively.

\section{Results}

Mean coefficient of variation of FASS total score was $13.0 \%$ between examiners and $8.3 \%$ between days. FASS total score (first basal) correlated with NUDS score $\left(r_{p}=-0.748\right)$ and IAPS stage $\left(r_{s}=0.783\right)$.

Table 3 shows the FASS total score variations during the trial. The Friedman test did not show significant changes either according to time ( chi-square $=5.29 ; \mathrm{df}=3$ ) or according to treatment (chi-square $=2.46 ; \mathrm{df}=3$ ). A similar analysis was

\begin{tabular}{llc}
\hline \multicolumn{2}{l}{ Table 2: Functional Ataxia Scoring Scale (FASS, ${ }^{5}$ modified) } \\
\hline \hline & \multicolumn{1}{c}{ Disability Score } \\
\hline A. Eye Movements & $0-20$ \\
1) fixation instability & $0-4$ & \\
2) gaze paresis & $0-4$ & \\
3) abnormal smooth pursuit & $0-4$ & \\
4) abnormal saccades & $0-4$ & \\
5) nystagmus & $0-4$ & \\
B. Lingual movements and speech & & $0-30$ \\
1) tongue protrusion and retraction & $0-10$ & \\
2) standard sentence repetition & $0-10$ & \\
3) conversation & $0-10$ & \\
C. Upper limb coordination & $0-10$ & \\
1) finger-to-nose & $0-10$ & \\
2) diadokokinesia & $0-10$ & \\
3) button & $0-10$ & \\
4) unbutton & $0-10$ & \\
D. Lower limb coordination & $0-10$ & \\
1) toe-to-finger & & $0-40$ \\
2) foot tapping & & $0-180$ \\
E. Gait & & \\
F. Stance & & \\
Total &
\end{tabular}

$0=$ Normal; $180=$ Maximal disability.

performed on subtotal scores. Only the stance score varied significantly according to times (first basal mean score $\pm S D=18$ \pm 8 ; first treatment $=17 \pm 9$; second basal $=16 \pm 9$; second treatment $=16 \pm 9 ;$ chi-square $=8.93 ; \mathrm{df}=3 ; \mathrm{p}=0.03$ ).

As for the manual dexterity test, no difference between trealments was found (chi square $=0.88 ; \mathrm{df}=3$ ), whereas a significant improvement with time was evident (first basal $=29 \pm 11$; first treatment $=32 \pm 13$; second basal $=33 \pm 12$; second treatment $=33 \pm 13$; chi-square $=17.2 ; \mathrm{df}=3 ; \mathrm{p}<0.005$ ).

Statistical analysis of writing during the trial did not show significant variation either between times (chi-square $=2.48$, df $=3$ ) or between treatments (chi-square $=3.84 ; \mathrm{df}=3$ ). 
Table 3: FASS Score According to Times and Treatments

\begin{tabular}{ccccc}
\hline \hline No. & 1st Basal & $\begin{array}{c}\text { 1st } \\
\text { Treatment }\end{array}$ & 2nd Basal & $\begin{array}{c}\text { 2nd } \\
\text { Treatment }\end{array}$ \\
\hline 1 & 63 & 62 & 63 & 60 \\
2 & 64 & 55 & 55 & 53 \\
3 & 66 & 74 & 74 & 70 \\
4 & 68 & 64 & 65 & 66 \\
5 & 49 & 47 & 47 & 47 \\
6 & 78 & 77 & 77 & 73 \\
7 & 22 & 23 & 19 & 20 \\
8 & 96 & 99 & 96 & 90 \\
9 & 103 & 101 & 105 & 104 \\
10 & 74 & 76 & 69 & 64 \\
11 & 123 & 127 & 130 & 129 \\
12 & 118 & 117 & 115 & 118 \\
12 & 83 & 70 & 75 & 79 \\
14 & 18 & 13 & 10 & 12 \\
mean & 73 & 72 & 71 & 70 \\
(SD) & $(31)$ & $(32)$ & $(34)$ & $(32)$ \\
\hline & (AH) basal & AH & (PLA) basal & PLA \\
mean & 72 & 71 & 72 & 71 \\
(SD) & $(33)$ & $(32)$ & $(32)$ & $(33)$ \\
\hline
\end{tabular}

$\mathrm{AH}$ : amantadine hydrochloride; PLA: placebo. Trial sequence was $\mathrm{AH}-$ PLA in patients $1-7$, PLA-AH in patients $8-14$. Each value is the average score of the 3 evaluators.

Only two patients reported improvement, one of them (No. 4) after $\mathrm{AH}$, the other (No. 14) after each treatment. Sedation was reported after $A H$ in one case (No. 4).

One of the two ADCA patients (No. 2) had a 14\% improvement at FASS total score after $\mathrm{AH}$.

\section{Discussion}

Peterson et al. ${ }^{5}$ proposed FASS to evaluate the effects of $\mathrm{AH}$ in FD patients. They obtained a good response in all patients, although they did not indicate which FASS items improved. The scoring scale we used differed mainly in that cardiomyopathy and scoliosis were omitted, since modifications of these items appeared unlikely, writing was evaluated separately and a manual dexterity test was added.

This modified scale proved to be reproducible between examiners (mean variation coefficient $=13 \%$ ) and between days $(8.3 \%)$. Sensitivity was demonstrated by the wide range between patients ( $10-130$, see Table 3 ). Furthermore, correlation between FASS total score and disability (NUDS) and disease progression (IAPS) was good.

Statistical evaluation of the effects of treatment on the total score, the 6 subscores, writing and manual dexterity test showed no significant changes.

The analysis of the time effect (independent of type of treatment) showed an improvement of manual dexterity consistent with learning. The slight significance level obtained for stance is likely due to chance, since numerous significance tests were performed.

These results contrast with the $29.5 \%$ FASS improvement reported by Peterson et al., ${ }^{5}$ which increased to $45.5 \%$ in ambulatory patients. There were some methodological differences between the two studies. Peterson et al. used a dose of $1 \mathrm{mg} / \mathrm{lb}$ of AH syrup to a maximum of $100 \mathrm{mg}$. Since we had no patient of pediatric age ( $<14$ years) we used a fixed dose of $100 \mathrm{mg}$. Peterson et al. evaluated the patients $60 \mathrm{~min}$ after the drug administration and reported that the effect was present in the majority of them in 1 hour and then gradually dissipated over 3 - 4 hours. We preferred to postpone videotaping to $90 \mathrm{mins}$ since plasma peak of $\mathrm{AH}$ after a single oral dose is at $2.1 \pm 1.0$ hours (mean $\pm \mathrm{SD}$ ). ${ }^{9}$ The above discussed scoring scale modifications do not seem to account for the discrepancies in the results. The design of the studies differed in that only the evaluators were blind in Peterson's study, whereas both evaluators and patients were blind in our placebo-controlled study. However, even considering only the sequence $(\mathrm{AH})$ basal $-\mathrm{AH}$ in our study, which overlap the Peterson's experiment, no effect of AH was evident (see Table 3). A higher expectation of improvement in Peterson's patients might explain the positive results in that study.

As demonstrated by Bradley et al. ${ }^{10}$ evaluation of patients with neuromuscular disease (including spino-cerebellar degenerations) may be affected by the placebo effect since so-called objective tests are also influenced by patient cooperation, attention, effort, and motivation. Uncontrolled pilot studies may produce initial enthusiasm, but their results must be verified by controlled trials.

In conclusion, our results do not show any significant effect of a single dose of $\mathrm{AH}$ in $\mathrm{FD}$. Further studies are required to evaluate the chronic treatment, however, since $\mathrm{AH}$ is not free of side effects under long term administration, we believe that its use in FD is so far not warranted. More patients are needed to evaluate $\mathrm{AH}$ effects in patients with ADCA and other late onset spino-cerebellar degenerations in which Botez et al. ${ }^{6}$ suggested an $\mathrm{AH}$ effect greater than in FD.

\section{ACKNOWLEDGEMENTS}

This work was partially supported by CNR, Italy (grant 91.04180) and by Ministry of Education.

\section{REFERENCES.}

1. Harding AE. Classification of the hereditary ataxias and spastic paraplegias. Lancet 1983; i: 1151-1155.

2. Filla A, De Michele G, Caruso G, Marconi R, Campanella G. Genetic data and natural history of Friedreich's disease: a study of 80 Italian patients. J Neurol 1990; 237: 345-35I.

3. Chamberlain S, Shaw J, Rowland A, et al. Mapping of mutation causing Friedreich's ataxia to human chromosome 9. Nature 1988; 334: 248-249.

4. Rich SS, Wilke P, Schut L, Wance G, Orr HT. Spinocerebellar ataxia: localization of an autosomal dominant locus between two markers on human chromosome 6 . Am J Hum Genet 1987; 41: 524531.

5. Peterson PL, Saad J, Nigro MA. The treatment of Friedreich's ataxia with amantadine hydrochloride. Neurology $1988 ; 38: 1478-$ 1480.

6. Botez MI, Young SN, Botez T, Pedraza OL. Treatment of heredodegenerative ataxias with amantadine hydrochloride. Can J Neurol Sci 1991; 18: 307-311.

7. Campanella G, Filla A, De Falco FA, et al. Friedreich's ataxia in the south of Italy: a clinical and biochemical survey of 23 patients. Can J Neurol Sci 1980; 7: 351-358.

8. Canter GJ, De la Torre R, Mier M. A method for evaluating disability in patients with Parkinson's disease. J Nerv Ment Dis 1961; 133: 143-147. 
9. Hayden FG, Minoche A, Spyker DA, Hoffman HE. Comparative single-dose pharmacokinetics of amantadine hydrochloride and rimantadine hydrochloride in young and elderly adults. Antimicrob Agents Chemoter 1985; 28: 216-221.
10. Bradley WG, Badger GJ, Tandan R, et al. Double-blind controlled trials of Cronassial in chronic neuromuscular diseases and atixiit. Neurology 1988; 38: 1731-1739. 